Journal of Advanced College of Engineering and Management, Vol. 5, 2019

\title{
EARTHQUAKE-INDUCED SHALLOW LANDSLIDE SUSCEPTIBILITY ASSESSMENT OF GORKHA DISTRICT
}

\author{
Tapendra Kumar Shahi
}

Geotech Engineer, Seismo Tech Engineering Consultancy Pvt. Ltd

\begin{abstract}
Nepal is very seriously affected by landslides every year causing loss of life and property. Large scale earthquakes that occurred in different time periods such as on 15th January, 1934 or that on 25th April 2015 have proved Nepal as seismically vulnerable -place. Nepal has witnessed several landslides during and after the earthquake events making some areas of land quite vulnerable for settlement and other usages. Therefore in order to minimize the impacts of landslides caused due to earthquakes, highly susceptible locations should be identified and spatial planning is made accordingly. Considering topographic effects in amplification of earthquake ground motion, Uchida et al. (2004) have developed a topographical parameter based empirical description of landslide susceptibility during an earthquake. In this research, the method proposed by Uchida et al. (2004) is utilized in raster GIS and landslide susceptibility analysis is performed in the study area of SulikotGaupalika of Gorkha district, Nepal which was severely hit by several landslides due to "Gorkha Earthquake 2015". The landslide inventory map of SulikotGaupalika due to "Gorkha Earthquake 2015" is obtained and is correlated with landslide susceptibility values as obtained by using Uchida et al. (2004). The analysis shows that the method proposed by Uchida et al. (2004) is more than $68.9 \%$ accurate in delineating the probable locations of earthquake induced landslides. By calibrating landslide data and landslide susceptibility values in a small site (i.e. SulikotGaupalika) within the study area, a final landslide susceptibility map is prepared for the whole study area of Gorkha district. The resultant susceptibility map is very useful for planning settlements, development activities and reconstruction planning.
\end{abstract}

Keywords: Earthquake; Landslides; Susceptibility; Spatial Planning; Nepal

\section{Introduction}

\subsection{Background}

Nepal is mountainous country of geologically young mountains and most of the infrastructures, settlements and utilities fall in the mountainous region.Nepal is characterized by adverse climatic conditions along with high relief, steep slopes, high seismicity, and fractured and weathered rocks making it prone to landslides. The Nepal Himalayan range is sitting on the boundary of two massive tectonic plates - the Indian and Eurasian plates. The collision of these plates has made the region tectonically active, occurring frequent earthquakes in Nepal which can be seen from the past records.Nepal has witnessed at least one major earthquake per century.

The earthquake events are capable of triggering new landslides and reactive old ones in Nepal as can be seen from the 25th April 2015 Gorkha Earthquake which triggered many landslides in Gorkha and surrounding districts. As per K. Robacket. al (2017), Gorkha earthquake and aftershock sequence produced at least 25,000 landslides throughout the steep Himalayan Mountains in central Nepal and caused destruction to infrastructures, utilities and settlements.Coseismic landslides have long been recognized as important secondary hazards of earthquakes in mountainous regions and potential contributors to mountain-scale erosional budgets (Keefer, 1994, Li et al., 2014).Also the impact of earthquake-induced landslides is more in Nepal as terrain in mountainous areas is steep, and most of the flatter ground is used for crop production. The rural residential villages and townships are therefore often located on or along ridgelines where due to the ridge amplification effects, are more susceptible for earthquake-induced landslides.The continuing risk due to earthquake induced landslides make it necessary to carryout landslide susceptibility analysis and locate the possible vulnerable zones so as to minimize the risk of loss of life and property. 


\subsection{Study Area}

\subsubsection{Location of Study Area and Details}

The area of study in this research is the Gorkha district. Geographically, the area lies between $27^{\circ} 15^{\prime}$ and $28^{\circ} 45^{\prime}$ North and between $84^{\circ} 27^{\prime}$ and $84^{\circ} 58^{\prime}$ East and is extended between the altitudes $228 \mathrm{~m}$ to $8163 \mathrm{~m}$ asl. Geologically, Gorkha district extends from Tibetan-Tethys Himalayan Zone in North to Lower Himalayan Zone in the South with majority central area lying in Higher Himalayan Zone. It is characterized by rugged topography and steep slopes with gradient from 0 to more than 80 . On 25 April 2015, a 7.8 magnitude earthquake with the epicenter located at Barpak, Gorkha hit Nepal causing massive destruction and several casualties and Gorkha was one of the severely affected district. The earthquake activated or reactivated numerous landslides in Gorkha district which caused major damage to settlements and infrastructures and it will pose a continuing risk.
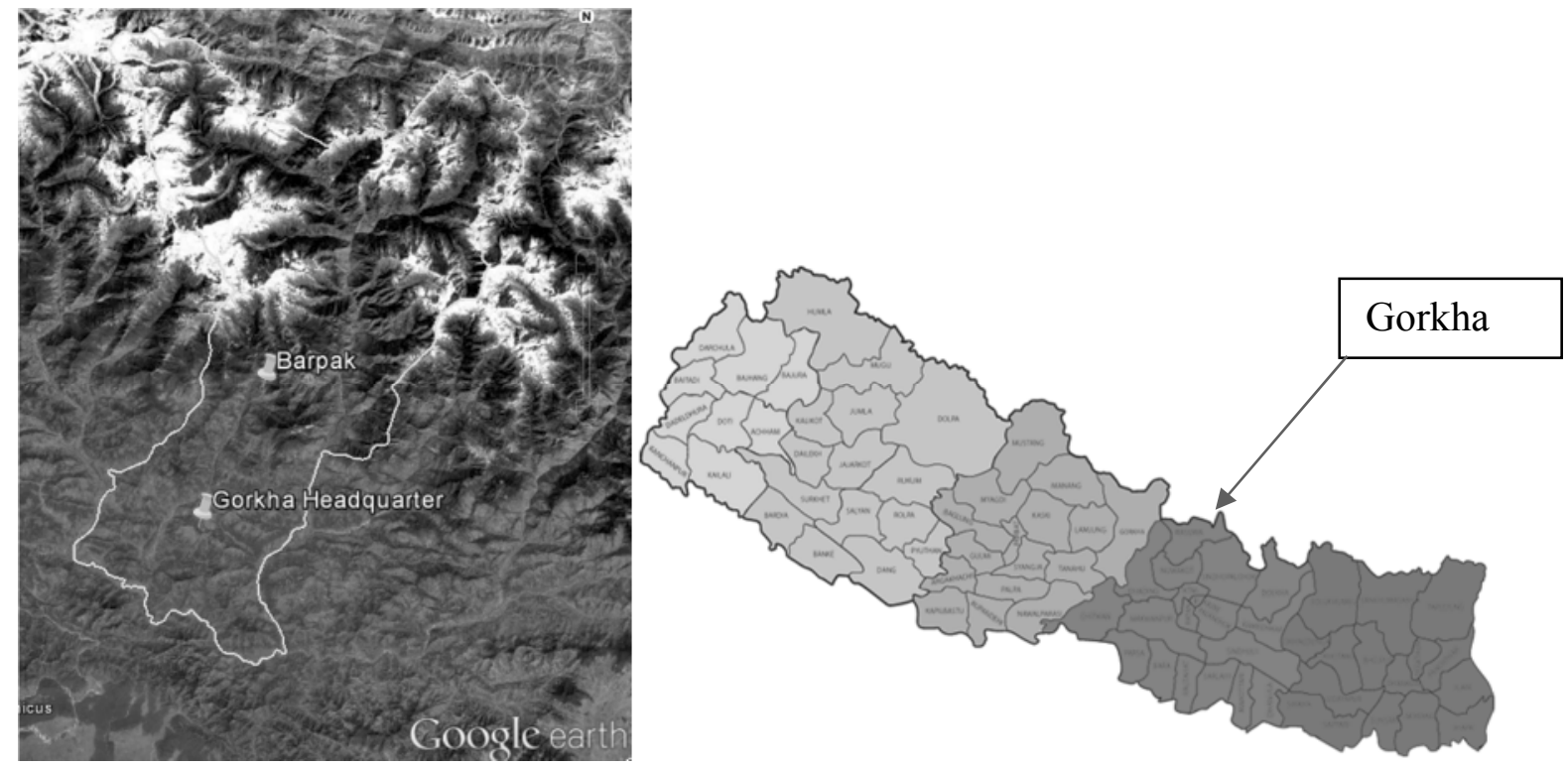

Fig 1-1 Location of Study Area

Developing an accurate landslide inventory map is a primary component of landslide susceptibility mapping. In the study area, area of SulikotGaupalika which is the epicenter of Gorkha Earthquake 2015 witnessed many earthquake-induced landslides which can be clearly identified by the Google Earth images taken immediately after the earthquake. Thus for the purpose of accurate landslide mapping, SulikotGaupalika has been selected as an ideal sub-site within the study area. Geographically, the SulikotGaupalika lies between $28^{\circ} 03^{\prime}$ and $28^{\circ} 22^{\prime}$ North and between $84^{\circ} 39^{\prime}$ and $84^{\circ} 48^{\prime}$ East and is extended between the altitudes $480 \mathrm{~m}$ to $5438 \mathrm{~m}$ asl. It is the central region of Gorkha district. It is the region which was severely hit by 25th April 2015 earthquake both by shaking and earthquake induced geohazards, mainly landslides. Various slopes in the area have been unstable and are vulnerable for future sliding. Also the mountains located within this area are characterized by topographical features typically associated with seismic energy amplification. The Figure 1.2 below shows the location of SulikotGaupalika within the Gorkha district. Location of Barpak, the epicenter of Gorkha earthquake is also marked within Sulikot. 
Journal of Advanced College of Engineering and Management, Vol. 5, 2019

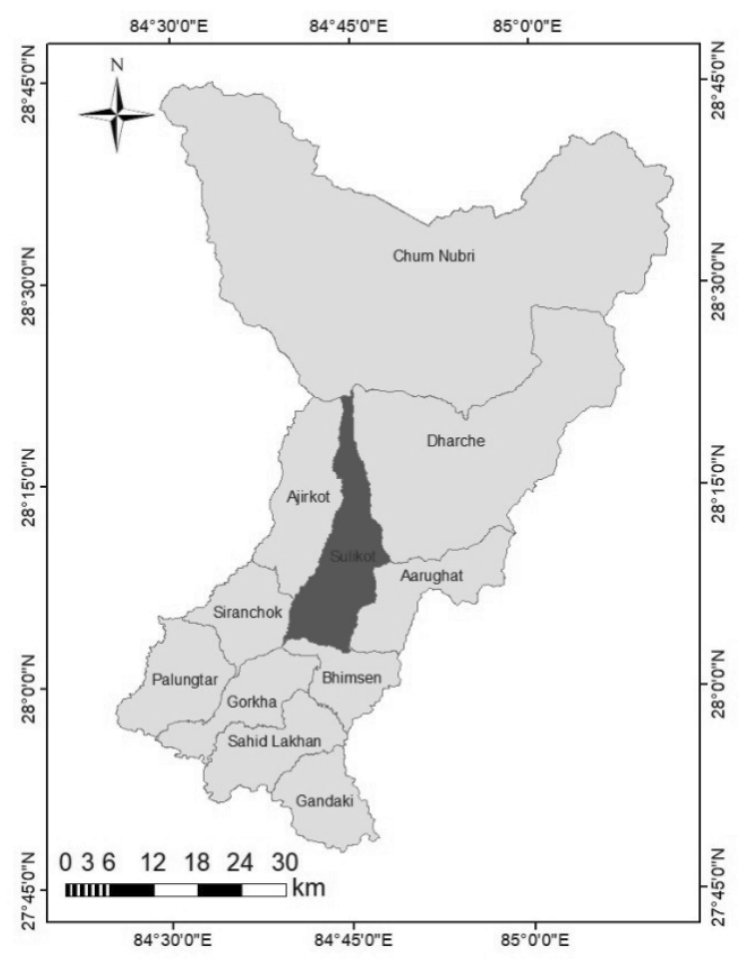

Figure 1-2 Sub-site selected from study area for landslide inventory mapping

\subsubsection{Geology and Tectonic Settings}

Geologically, Gorkha district extends from Tibetan-Tethys Himalayan Zone in North to Lower Himalayan Zone in the South with central area lying in Higher Himalayan.

Thus study area consists of different rock types in different geological zones.

The Main Central Thrust (MCT) and South Tibetan Detachment System (STDS) pass through the Gorkha district. These are the sources of weakness and make the area tectonically active and seismically vulnerable.

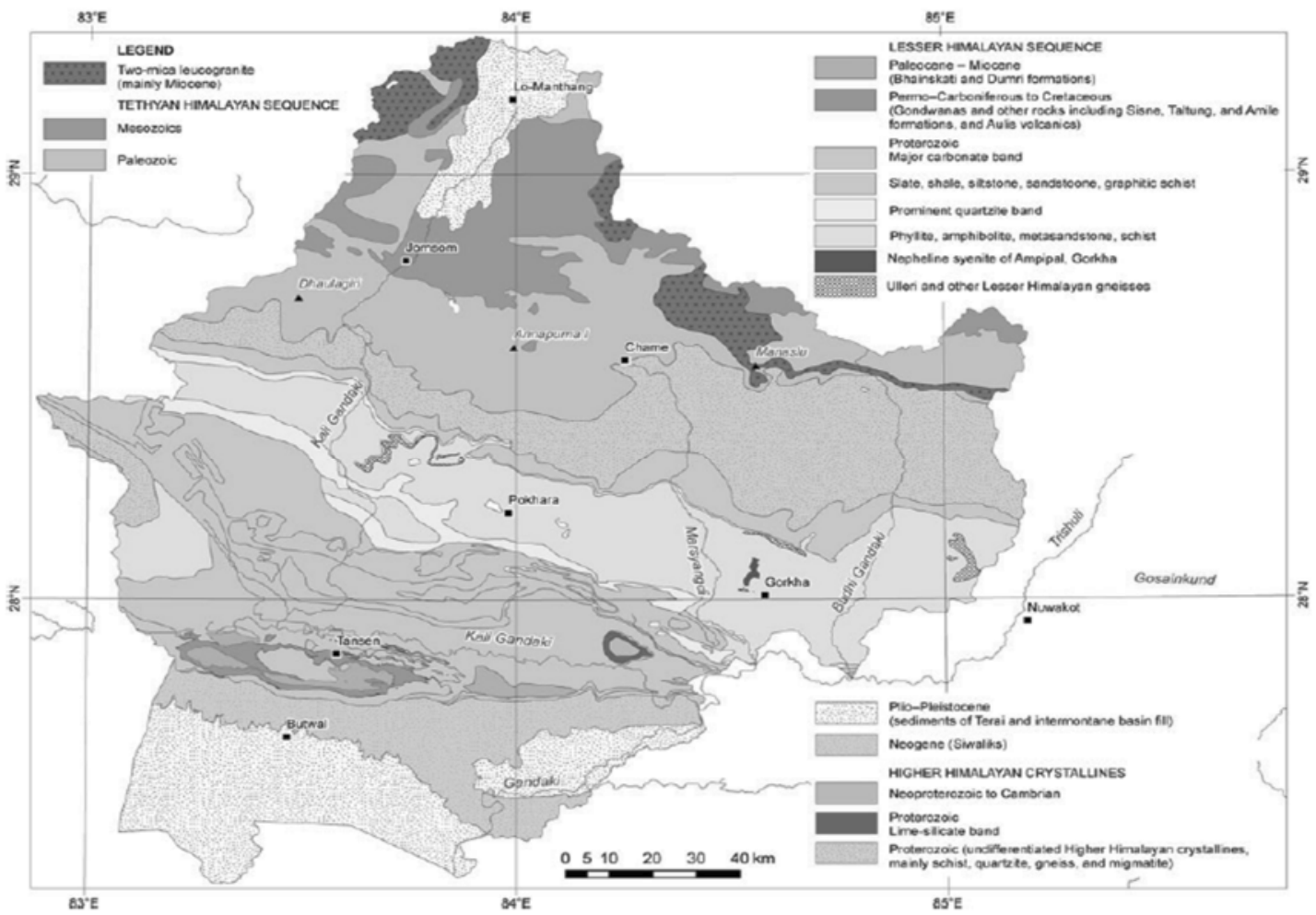

Fig1-3 Simplified geological map of the Gandaki region (Dhital 2014) 


\section{Literature Review}

With the application of aerial photographs and field verifications, landslides induced by earthquakes have been mapped and analyzed in California, El Salvador, Taiwan, Japan, Italy and Pakistan (e.g., Wilson and Keefer 1985; Harp and Keefer 1990; Harp and Jibson 1996; Jibson et al. 2000).

Several methods have been developed for the evaluation of hazards represented by earthquakeinduced landslides, including statistical analysis (Keefer 1984, 2000; Lee and Evangelista 2006) and a deterministic method (Mankelow and Murphy 1998; Van Westen and Terlien 1996), both of which aim to quantify earthquake induced landslide susceptibility and hazard zonation

The effect of topography on the earthquake ground motion and nature and spatial distribution of earthquake-induced landslides have been well documented. Observation noted extremely high accelerations during the earthquakes at sites located on topographic ridges (eg. Davis and West 1973; Bannister et al. 1990; Geli et al. 1988; Clouser and Langston 1995; Chávez-García et al. 1996; Miles and Keefer 2000; Lin et al. 2003).

Observations of the damage patterns of earthquakes, such as the 1987 Whittier Narrows, California earthquake, the 1989 Loma Prieta (California) earthquake, the 1994 Northridge, California earthquake, the 1999 Chi-Chi earthquake of Taiwan, the 2004 Chuetsu earthquake of Niigata Prefecture, Japan, and the 2005 Kashmir earthquake of Pakistan also indicate the occurrence of intense shaking in elevated areas of rugged topography (Hasegawa et.al. 2009)

Study on the spatial distribution of coseismic landslides by the Wenchuan Earthquake in the Beichuan area of China shows that the most of the landslides were shallow and occurred on convex slopes or at ridge tops (Chuan Tang et.al. 2011).

Also the topographical effects on the amplification of seismic waves have been observed during the $25^{\text {th }}$ April 2015 Gorkha Earthquake where the landslide frequency was noted to be much higher on or near the crests (ridges) of hills and mountains and most of the landslides were shallow (Kevin Roback et.al. 2017; EERI report 2016, Ranjan Kumar Dahal 2015, ICIMOD Research Report 2016/1).

Nishida et.al. (1997) indicated that topographical factors contributing to earthquake triggered shallow landslide were both the slope gradient and the slope curvature.

Motivated by findings regarding the effect of topography on the amplification of earthquake ground motion and the most of the co-seismic earthquakes being shallow, Uchida et.al. (2004) have developed a topographical parameter-based empirical relationship for shallow landslide analysis during an earthquake. In this method, the earthquake-induced shallow landslide analysis has been carried out using DEM-based intrinsic parameters (slope gradient and slope curvature) and one extrinsic parameter (an earthquake) with in the geographical information system (GIS).Uchida et.al. (2004) first developed the methodology for Rokko mountains, which is underlain by granite and covered by forest vegetation, considering Hyogo-ken Nambu Earthquake of 1995 using linear discriminant analysis and derived the landslide probability function (or discriminant score) as follows:

$$
F=0.075[\theta]-8.9[\varepsilon]+0.0056\left[a_{\max }\right]-3.2
$$

Where $F$ is the landslide probability function or discriminant score, $\theta$ is the slope angel in degree, $\varepsilon$ is the average curvature, and $a_{\max }$ is the maximum ground acceleration in gal $\left(1 \mathrm{gal}=0.01 \mathrm{~m} / \mathrm{s}^{2}\right)$. The landslide susceptibility increases with the increase in the value of $F$. They then examined the applicability of the method to other regions and/or other earthquakes with different wave characteristics such as in Kozushima Island, underlain by predominantly tuff and covered by forest, considering Kozushima earthquake $(M=6.5)$ of 2000 and in Niigata-ken Chuitsu region, underlain by 
tertiary sedimentary rock and covered by forest and paddy field, considering the Niigata-ken Chuitsu Earthquake of October 23, 2004. Positive relationship between discriminant score and percentage of landslide occurrence was obtained for both Kozushima Island and Chuitsu region. They concluded that the proposed approach is highly applicable and practical to predict dangerous area of the seismic shallow landslide occurrence. The method is not so applicable for the deep-seated landslides.

The method proposed by Uchida et al. (2004) have also been utilized by Shuichi Hasegawa et al. (2009) for carrying landslide susceptibility analysis in the study area of Nishiyami Town of Kashiwazaki city, Japan. The analysis suggest that the method is more than $78.14 \%$ accurate in delineating the probable locations of earthquake induced landslides.

Ranjan Kumar Dahal (2015) applied Uchida et.al. (2004) method for the earthquake induced slope failure susceptibility in the Mechi Highway of Eastern Nepal considering earthquake measuring 6.9 in Richter scale of September 18, 2011 with a prediction rate of $83.44 \%$.

\section{Methodology}

The topographic maps published by the Survey Department, Government of Nepal and Google Earth images were used for the preparation of inventory map. Peak ground acceleration data of Gorkha district due to "Gorkha earthquake 2015" were collected from the Department of Mines and Geology and USGS websites. For the preparation of the Landslide susceptibility Map, ArcGIS 10.3 and ILWIS 3.3 software is used and the method adopted is that proposed by Uchida et al. $(2004,2006)$.

\subsection{Landslide Inventory Map}

Developing an accurate landslide inventory map is a primary component of landslide susceptibility mapping. Preparation of landslide inventory map is the most important and initial step for landslide susceptibility analysis. The existing landslides are taken into consideration for predicting and evaluating susceptible areas as future landslides are likely to occur in same geological, hydrological and geomorphic condition as those in the past.

\subsection{DEM-based Earthquake-Induced Landslide Analysis}

Uchida et al. $(2004,2006)$ derived a landslide probability function based on discriminant analysis using slope, average curvature and maximum ground acceleration without considering geology and other intrinsic factors. Uchida et al. (2004) defined average curvature as the average of the maximum and minimum curvatures of all geodesics on the curved slope. In raster GIS, the average curvature, $\varepsilon$, can be derived from the following relationship:

$$
\varepsilon=\frac{\frac{\partial^{2} f}{\partial x^{2}}\left\{1+\left(\frac{\partial f}{\partial y}\right)^{2}\right\}+\frac{\partial^{2} f}{\partial y^{2}}\left\{1+\left(\frac{\partial f}{\partial x}\right)^{2}\right\}-2 \frac{\partial f}{\partial x} \frac{\partial f}{\partial y} \frac{\partial^{2} f}{\partial x \partial y}}{\sqrt{2\left(1+\left(\frac{\partial f}{\partial x}\right)^{2}+\left(\frac{\partial f}{\partial y}\right)^{2}\right)^{3}}}
$$

Where $f$ is the pixel value of a DEM generated from the contour map and $\mathrm{x}$ and $\mathrm{y}$ are the local coordinates. Concave slope gives a positive curvature and convex slope gives a negative curvature value. On the basis of average curvature defined in Eq. (1), Uchida et al. (2004) derived the landslide probability function from discriminant analysis as follows:

$F=0.075[\theta]-8.9[\varepsilon]+0.0056\left[a_{\max }\right]-3.2$. 
Where $F$ is the landslide probability function or discriminant score, $\theta$ is the slope angel in degree, $\varepsilon$ is the average curvature, and $a_{\max }$ is the maximum ground acceleration in gal $\left(1 \mathrm{gal}=0.01 \mathrm{~m} / \mathrm{s}^{2}\right)$. Pixels having positive $F$-value always have the potential to fail during an earthquake, and negative $F$-value suggest the slope will not fail during an earthquake. Equations (3.1) and (3.2) are easily applicable to DEM in the GIS platform.

\subsection{Data Analysis}

For this study, a thematic data layer of slope and average curvature were prepared in GIS. DEM data (20 m x $20 \mathrm{~m}$ pixel) were considered as basic data sources to generate these layers. ArcGIS 10.3 software was used. GIS has a built-in command for slope calculation and Eq. (3.1) was used in ILWIS 3.3 for the average curvature calculation. The PGA value of Gorkha district due to Gorkha earthquake 2015 as downloaded from USGS websites was used for the analysis. The landslide susceptibility index ( $F$-value was determined from Eq. (3.2). Finally, a spatial distribution of $F$-value was prepared in GIS raster.

\subsection{Preparation of Susceptibility Map}

The $F$-value are qualitatively examined with the help of success rate curve. In statistical landslide susceptibility analysis, the success rate is a measure of goodness of fit (Lee 2004; Dahal RK et al. 2008a) and for this research, success rate can be a measure of the predictive power of landslide susceptibility values (here, $F$-value) because calculated susceptibility values do not have any statistical relationship with existing landslides (as they do in other statistical landslide susceptibility analysis techniques).

To obtain the success rate curve for the $F$-value the calculated index values of all pixels in the map are sorted in descending order. The ordered pixel values are subsequently categorized into 100 classes with $1 \%$ cumulative intervals and an $F$-value map is prepared using slicing operation in ILWIS 3.3. The $F$-value map is crossed with the landslide inventory map and the success rate curve is prepared from cross table values.

To compare the landslide susceptibility values, the area under the curve (Lee 2004, Dahal RK et al. 2008a) is estimated from the success rate graphs. The area under the curve qualitatively measures the success rate or prediction rate of the $F$-value. A total area equals to one denotes perfect prediction accuracy. Alternatively, when the area under the curve is less than 0.5 , the analysis is invalid.

To construct the classified susceptibility map of the selected sub-site, the reference success rate curve is created and the corresponding $F$-value for susceptibility levels of $30 \%, 50 \%, 70 \%$ and $90 \%$ (with $F$-value ranging from low to high) are calculated. Five landslide susceptibility classes are established: very low (less than 30\%), low (30-50\%), moderate (50-70\%), high (70-90\%) and very high (more than $90 \%$, i.e. the highest $F$-value).

\section{Methodology}

\subsection{Landslide Inventory Map}

Landslide inventory mapping of study area of Sulikot due to Gorkha earthquake 2015 was performed by the study of the Google Earth images of the area comparing images just before and after the earthquake. To verify that the landslides are earthquake-induced and to correct the inventory map, fieldwork was carried out on December 5 to 8, 2017 to observe the landslide scars. All landslides sites around the Barpak were visited. Although the inventoried landslides from Google Earth successfully matched the field condition, few of the landslides were found to have caused due to rainfall and existed prior to earthquake and were removed from inventory mapping. Also few landslides that were 
not visible in the Google earth images taken after earthquake events were included in the inventory mapping as these landslides were claimed by the local residents to have occurred due to Gorkha earthquake 2015. In this way, a final inventory map of earthquake-induced landslides was prepared for analysis. The landslide inventory layer map of the Sulikot area is shown below in Figure 4-1.

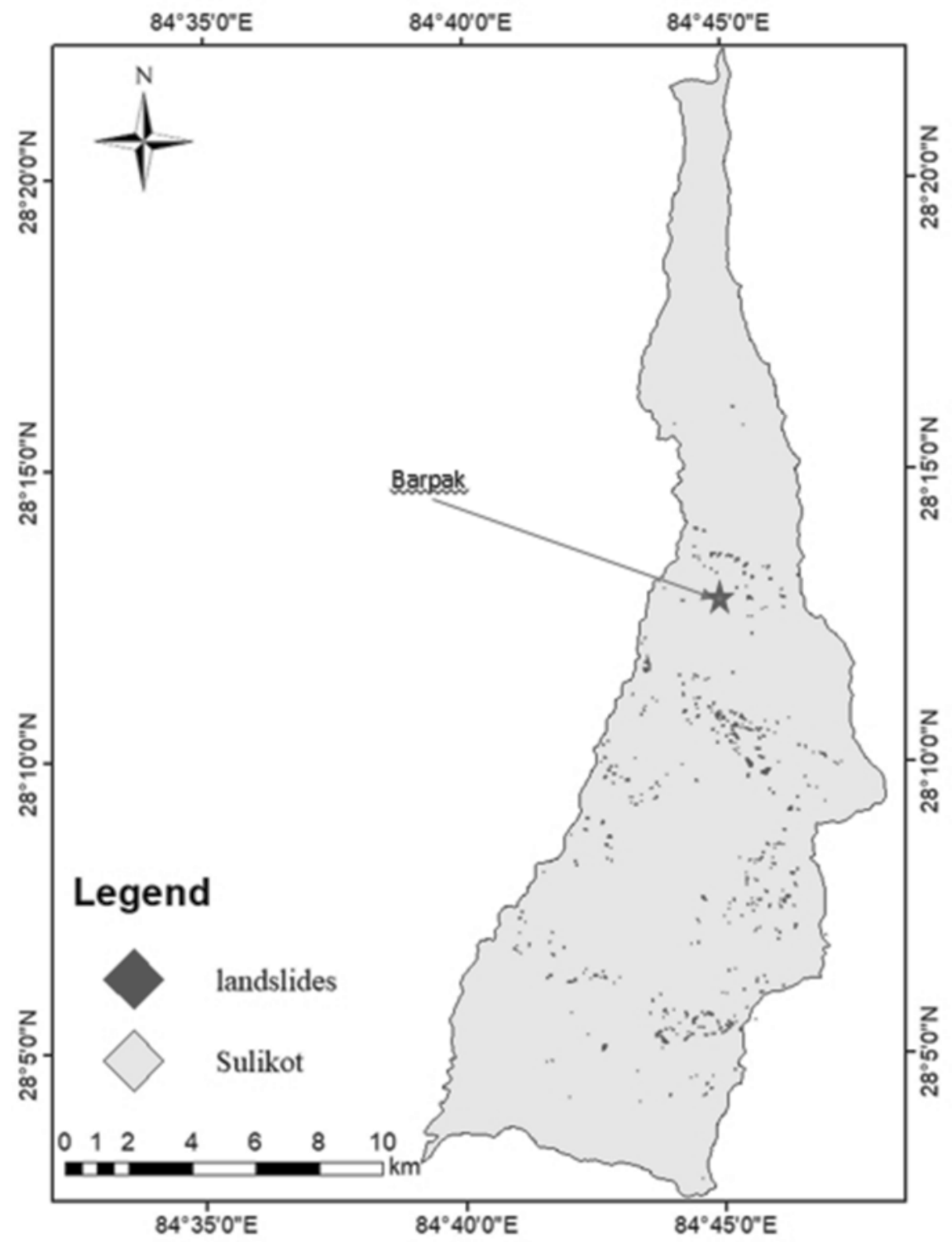

Fig 4-1: Landslide Inventory map of Sulikot area of Gorkha District.

\subsection{Digital Elevation Model (DEM) of Sulikot Area}

From this contour map, DEM (20m x 20m pixel) was constructed in GIS and it was used as basic data sources to generate parameter maps such as slope and curvature layers. The DEM of the sub-site of the study area is shown below. 
Journal of Advanced College of Engineering and Management, Vol. 5, 2019
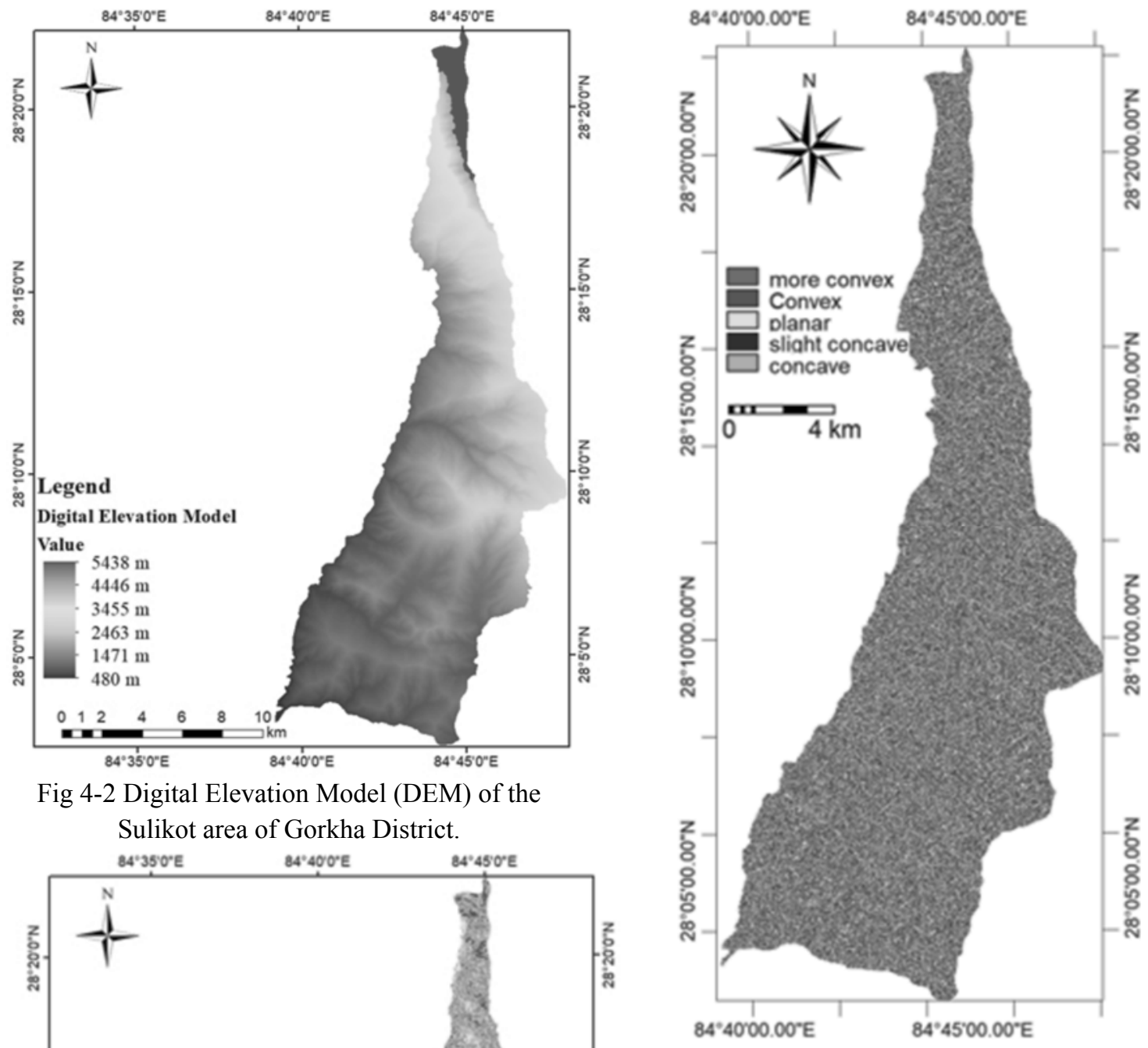

Fig 4-3: Curvature map of the Sulikot area of Gorkha District.

Fig 4-4: Curvature map of the Sulikot area of Gorkha District. 


\subsection{Peak Ground Acceleration (PGA)} Value Map of Sulikot Area Due Gorkha Earthquake

The GIS shape file of PGA due to $25^{\text {th }}$ April 2015 Gorkha Earthquake for the large regional area was available in USGS website. From this file, the PGA shape map forSulikot area was extracted and converted to raster form in GIS with cell size of $20 \mathrm{~m} \times 20 \mathrm{~m}$, which is shown below.

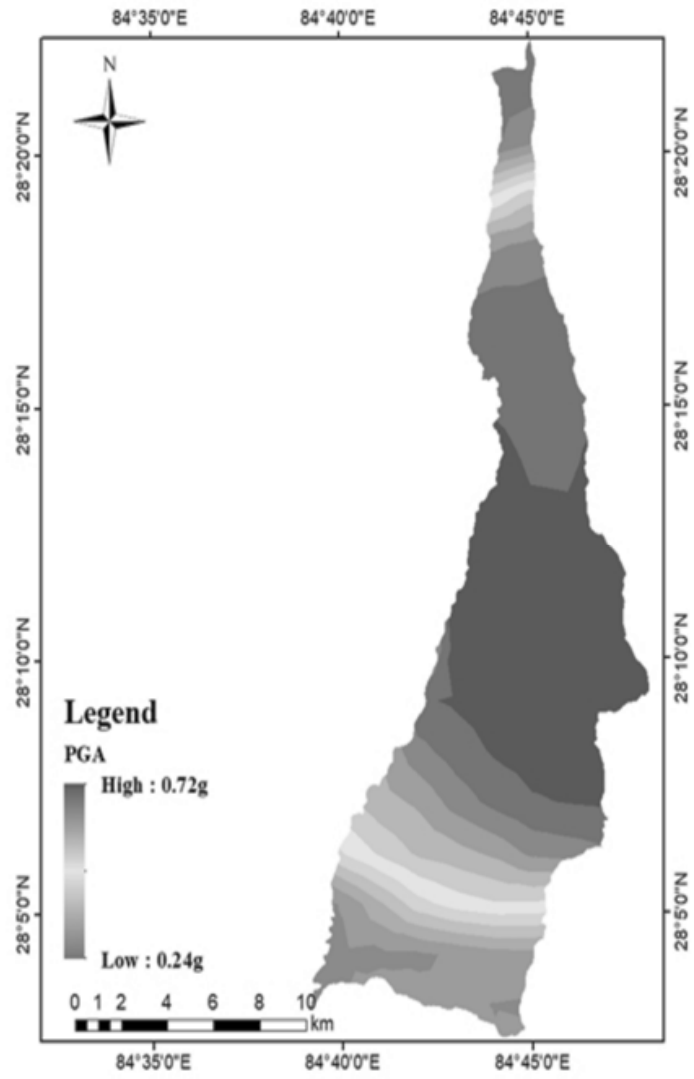

Fig 4-5: Peak ground acceleration (PGA) map of Sulikot area of Gorkha District due to $25^{\text {th }}$ April Gorkha Earthquake. (USGS 2015c)

\subsection{Landslide Probability Function (F-value) Map of the Selected Sub- site}

Landslide probability function (F-value) was calculated using equation (3.2) for the each pixels in the area in ILWIS Academic 3.3. Lower value of probability function indicates low potential of landslides due to earthquake and higher F-value indicates high susceptible for earthquake-induced landslides. The map showing F-value distribution is shown below.

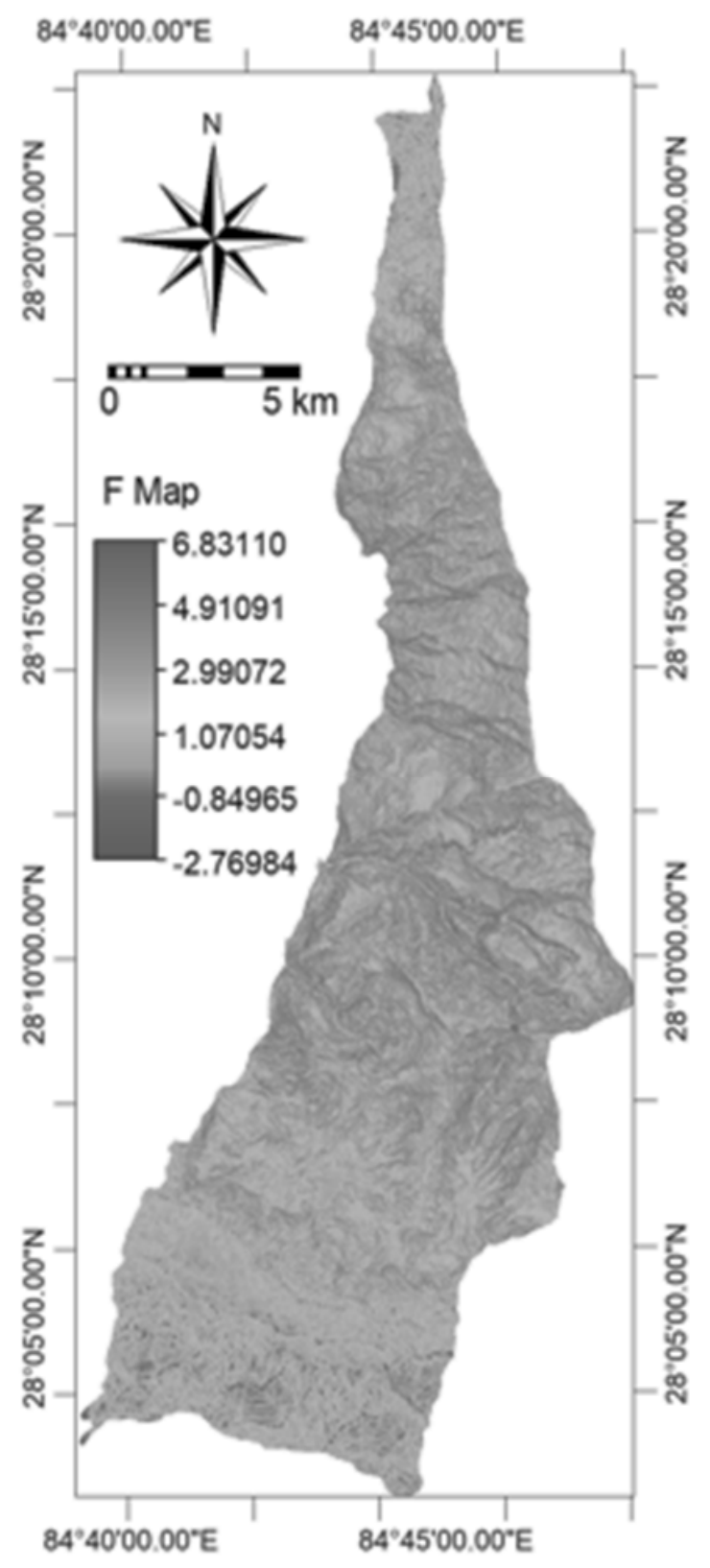

Fig 4-6: Landslide Susceptibility Index map of Sulikot area of Gorkha District. 
Journal of Advanced College of Engineering and Management, Vol. 5, 2019

\subsection{Success Rate Curve of Susceptibility map for the selected sub-site}

The success rate curve was drawn from cross table values obtained by crossing F-map by inventory map. The success rate curve is shown below.

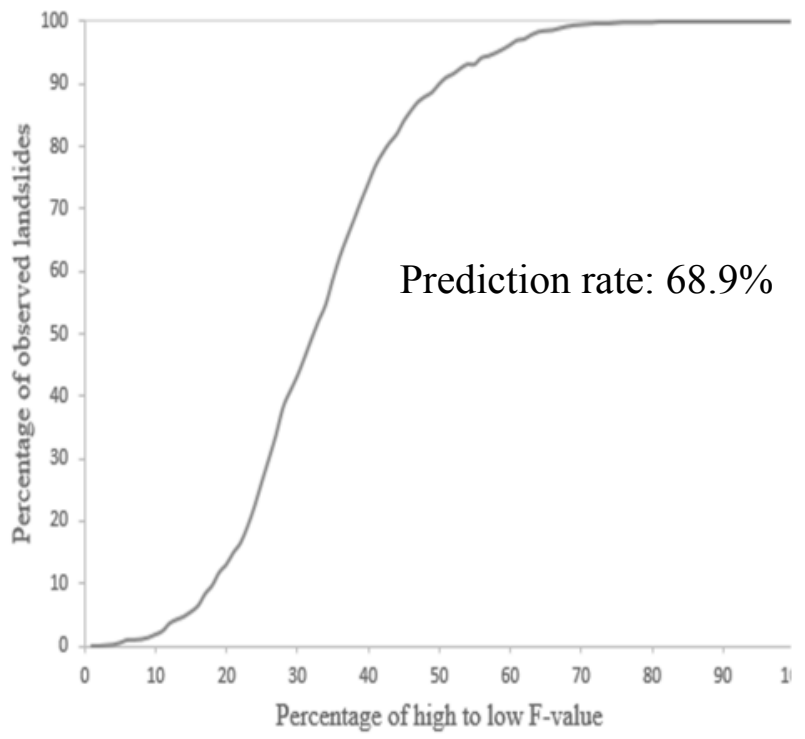

Fig 4-7: Success rate curve and prediction rate of susceptibility map for the Sulikot area of Gorkha district.

In this study, the area under the success rate curve is 0.689 , indicating that the prediction rate is $68.9 \%$ and the analysis is valid. (Hasegawa et al. 2009)

\subsection{Landslide Susceptibility Map of The Selected Sub-site}

The corresponding $F$-values for susceptibility levels of $30 \%, 50 \%, 70 \%$ and $90 \%$ (with $F$ values ranging from low to high) were calculated.Final susceptibility map was then prepared. Five landslide susceptibility classes were established: very low (less than $30 \%$ ), low (30-50\%), moderate (50-70\%), high (70-90\%) and very high (more than 90\%). The susceptibility map of the sub-site prepared based on these intervals is shown in Figure 4.8

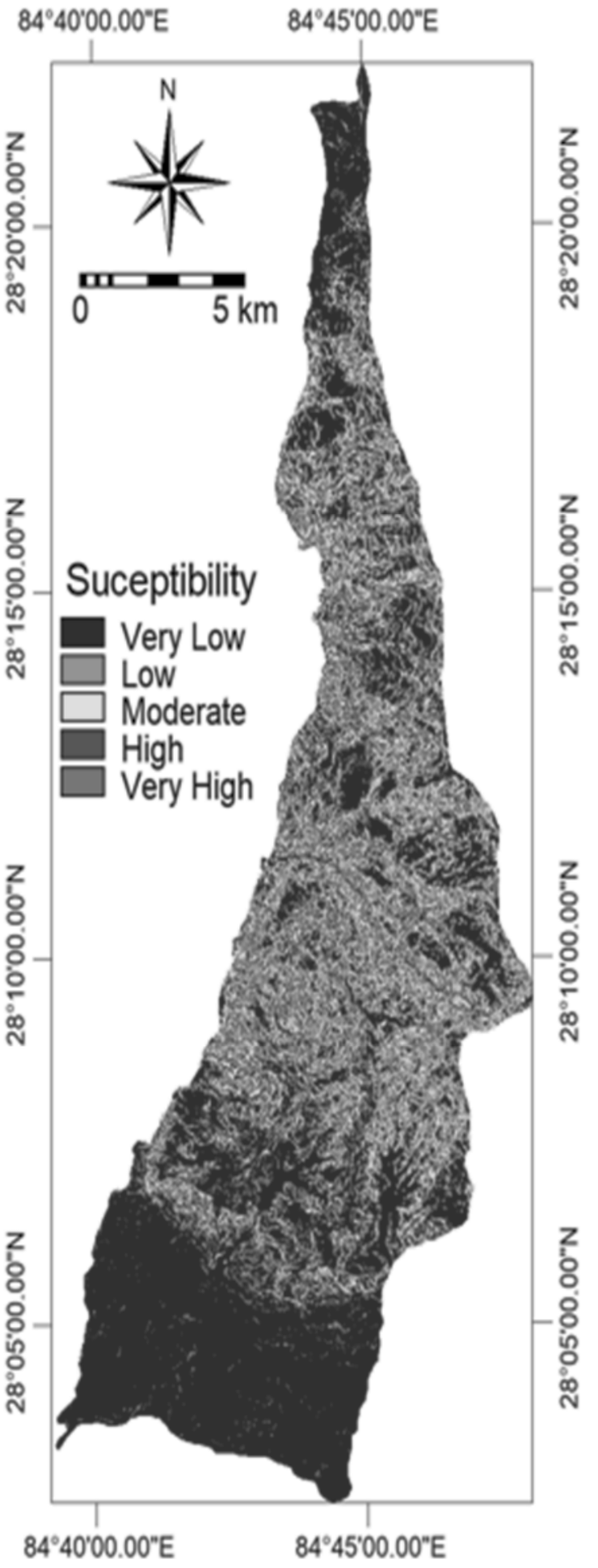

Fig 4-8: Susceptibility map of Sulikot area of Gorkha District. 


\subsection{Final Landslide Susceptibility Map of The Whole Gorkha District.}

As the prediction rate from success rate curve obtained for sub-site i.e. sulikot area is $68.9 \%$, the adopted analysis is valid and the same analysis was then adopted for whole Gorkha district to get final landslide susceptibility map of Gorkha district.

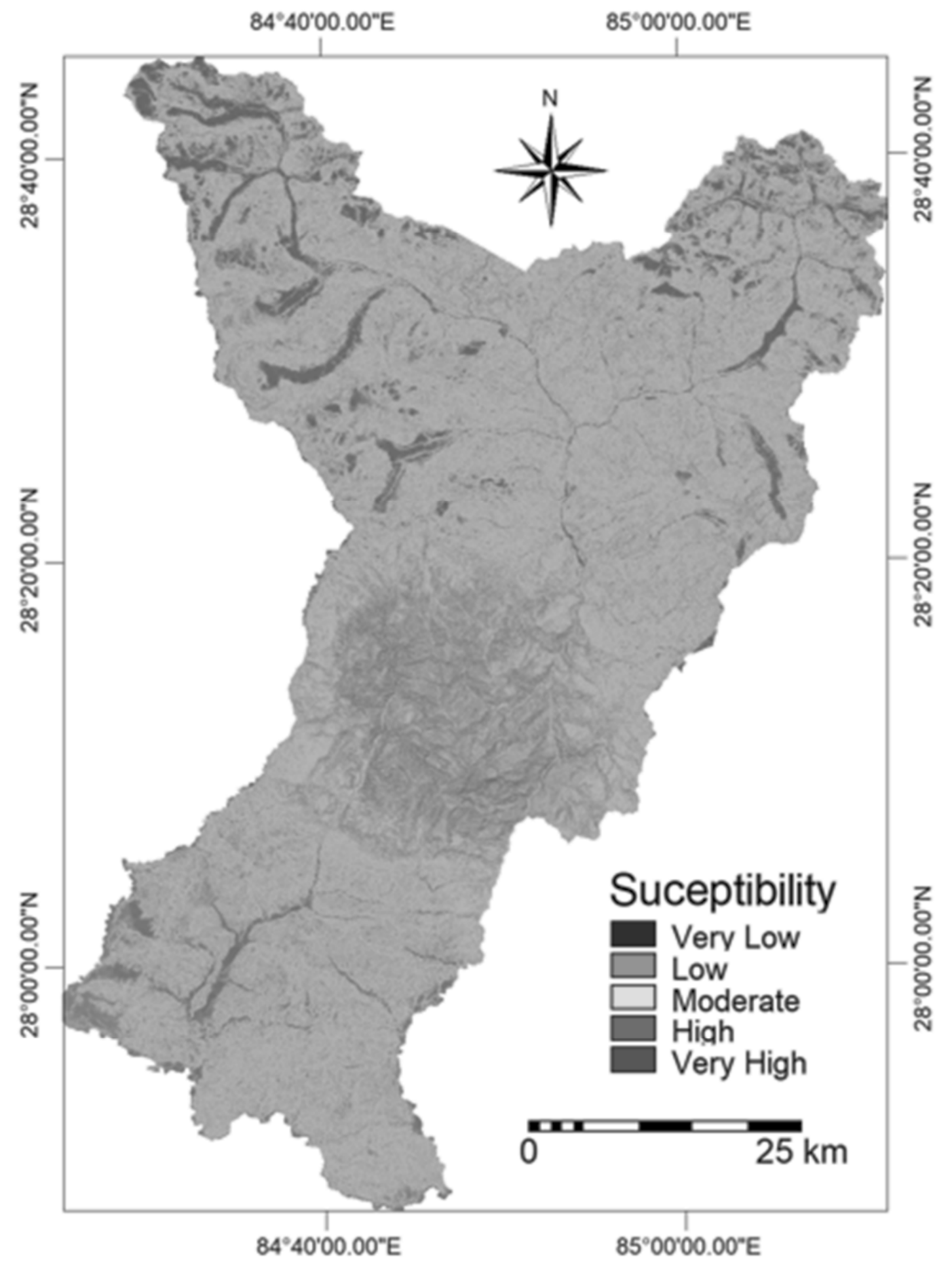

Fig 4-9: Susceptibility map of Gorkha District. 


\section{Conclusion and Recommendation}

\subsection{Conclusions}

The analysis shows that the evaluation of earthquake-induced landslide susceptibility and zoning is possible by applying the methodology as suggested by Uchida et.al. (2004) in combination with GIS techniques. The study was done in consideration with the concept of seismic topographic amplification for a study area of Gorkha district which was the epicenter of $25^{\text {th }}$ April 2015 Gorkha earthquake and was severely hit by the earthquake. Considering the susceptibility parameters such as slope and curvature and effect of ground acceleration, the coseismic landslide susceptibility was carried out successfully. It can be concluded that the precise DEM is adequate for the analysis of shallow earthquake-induced landslide susceptibility.The resultant susceptibility map of the ideal subsite shows $68.9 \%$ accuracy indicating that the analysis is valid $(>50 \%)$ and a similar scheme was then used for the whole Gorkha district. The final landslide susceptibility of the whole Gorkha district, which can be said to have predictive power of around $68.9 \%$, will be quite useful for regional scale planning.The susceptibility map shows high hazard in the ridges and area having higher slope with convex curvature and low hazard along valleys. The susceptibility is also considerably higher in the area with high ground motion.

\subsection{Recommendation}

There are rooms for improvement of the study. Following are some recommendation made based on the thesis work.

- $\quad$ The success rate of the susceptibility map depends also on how accurately the earthquakeinduced landslides have been mapped. The inventoried landslides through Google Earth images needs to be thoroughly checked through field visits. Here, only part of the area was visited to tally landslides in the field due to various constraints. There was some variations in the Google Earth images and actual site visits. The success rate can be increased and more accurate susceptibility maps may be prepared by conducting intensive field study.

- The susceptibility analysis in this study has been carried out considering PGA values due to $25^{\text {th }}$ April 2015 Gorkha Earthquake, which is site-specific. However more comprehensive susceptibility map of the area can be prepared by using probable future maximum ground acceleration of area for susceptibility analysis.

\section{References}

1. Dahal RK (2015) "Earthquake-induced Slope Failure Susceptibility in Eastern Nepal." Journal of Nepal Geological Society 49: 49-56

2. Dahal RK (2015) "Engineering Geological Issues after Gorkha Earthquake 2015 in Nepal - a preliminary understanding." 10th Asian Regional Conference of IAEG (2015)

3. Dhital MR (2015). Geology of the Nepal Himalayas, Regional Perspective of the Classic Collided Orogen". Springer International Publishing Switzerland 2015

4. EERI Earthquake Reconnaissance Team Report (2016) M7.8 Gorkha, "Nepal Earthquake on April 25, 2015 and its Aftershocks", Earthquake Engineering Research Institute, Oakland, California 
5. Hasegawa S, Dahal RK, Nishimura T, Nonomura A, Yamanaka M (2009) "DEM-based analysis of Earthquake-induced shallow landslide susceptibility". Geotechnical and Geological Engineering 27: 419-430

6. ICIMOD Research Report (2016/1) “The Impact of Nepal's 2015 Gorkha EarthquakeInduced Geohazards", International Center for Integrated Mountain Development (ICIMOD), Kathmandu.

7. "Nepal Disaster Report 2015", Ministry of Home Affairs (MoHA), Government of Nepal and Disaster Preparedness Network -Nepal (DPNet). 